\title{
The Malaysian Construction Industry's Risk Management in Design and Build
}

\author{
Hamimah Adnan \\ Department of Quantity Surveying \\ Faculty of Architecture Planning and Surveying \\ University Teknologi MARA, Malaysia \\ Tel: 60-3-5544-4935 E-mail: hamimah689@salam.uitm.edu.my \\ Kamaruzaman Jusoff (Corresponding author) \\ Yale University, Tropical Resources Institute \\ 210 Prospect St, New Haven, CT 06511, USA \\ Tel: 60- 203-676-7761Ｅ-mail: jusoff.kamaruzaman@yale.edu \\ Mohd Khairi Salim \\ Department of Quantity Surveying \\ Faculty of Architecture Planning and Surveying \\ Universiti Teknologi MARA, UiTM Shah Alam, Selangor, Malaysia
}

The research is financed by Universiti Teknologi MARA (UiTM), Shah Alam, Selangor,Malaysia (Sponsoring information)

\begin{abstract}
Over the past twenty years, there have been large-scale and expensive public works tenders that adopted design and build procurement (D\&B) contracts which consist of construction and civil engineering. Experts from the academic and construction circles have been studying the effective implementation of these tenders, the difficulties they encountered and the solutions for them. However, design and build (D\&B) projects have additional stages such as the pre-planning and design and post-operative stages compared to traditional construction projects. As a result, contractors are faced with a higher chance of project risk probability and impacts. The risks that were to be assumed by the original employer may be transferred to the design and build contractors by means of a written agreement. Risk Management involves appropriate handling of risks after evaluation and analysis to minimize the negative impacts risks have on the finance with the lowest costs. Risk management is applied to establish necessary guidelines and to obtain key indices for successful design and build projects for contractor to follow. The method incorporated in this research included literature review, questionnaire surveys and interviews. The encountered risk factors were compiled and placed in the right sequence. The possible ways of minimizing risks that design and build members have on the project according to the definition and implementation of risk management been also looked into. From the findings, it is recommended that contractors should have clear employer briefing, clear specifications and statement of needs, good quality of workmanship, implementing code of practice, key elements effective management, effective communication with all components of the project team and decisive action in the event of deviation from plans for a successful (D\&B) projects
\end{abstract}

Keywords: Risk Management, Design and build, Malaysian construction Industry

\section{Introduction}

The construction industry is a vehicle through which a nation's physical developments are activated by initiating projects from the blue print stage to the implementation. The implementation and materialization of such projects inevitably can bring about benefits to the people and the nation, thus satisfying the aspiration of national progress and 
growth and in up-lifting the status of the nation economically. At the implementation stages of developing a project the client has to make decisions on technical choices such as size, location and standard. By then the client should decide on a contract strategy regarding the best method to employ contractors for construction and other services. This would depend on his priorities on the cost of the project, construction time, quality or any secondary objective. Lack of a contract strategy in reference to risk allocation can produce very unpleasant surprises that will lead to future disputes. It is possible to find that contract duration and the processes involved are beyond the clients' initial expectations. Therefore, careful analysis for a contract strategy should lead to the selection of the right allocation of responsibilities, type of contract and tendering procedure for a project and eventually for the contract itself.

The increasingly complex and varying demands placed upon the construction industry by the clients do not only stem from the need to provide more sophisticated commercial and industrial working environments at minimum cost and maximum speed, but also from the fact that the organizations of the clients' are also complex in nature with different categories of consumers requiring discrete solutions to their procurement needs. The choice of a procurement method route for construction work is one of the many important decisions that construction clients have to make. An early decision on the preferred method of contract procurement is essential, as it will have an impact on the amount of the pre-contract work, the employers' financial and human resources, outlay for the completion of the project as well as issues such as risk transfer and allocation of responsibilities under the contract. Therefore, modern owners of constructed facilities are increasingly investigating a variety of alternative procurement methods. These methods include design-build, turnkey and construction management. To effectively service this market driven expansion of project delivery strategies in the construction community a fundamental understanding of owner's attitudes is required.

Design and build is an arrangement where contracting organization takes sole responsibility, normally on a lump sum fixed price basis, for the bespoke design and construction of a client's project (Masterman, 1992). Design and build is a procurement method where one entity or consortium is contractually responsible for both the design and construction of a project (Murdoch \& Hughes, 2000). In contract to the lump sum method, design and build has two concurrent phases. The clients enter into one contract with a design and build company that is responsible for project development and construction. The contractual arrangement is the simplest of the other contractual arrangement like management contracting (MC) and construction management (CM). There is one contract and one line of communication for the client. The designer-builder may be a single company that employs both the design and construction staff (known as $\mathrm{D} \& \mathrm{~B}$ ) or the design-builder may be a partnership of two or more design and construction companies (known as joint venture $\mathrm{D} \& \mathrm{~B})$. The objectives of this paper are two-folds: to identify common risks associated with design and build method and to make recommendation in order to mitigate the risks.

Construction is a dynamic and complex industry requiring enormous amounts of capital and resources to function efficiently. The factor of the size and diversity of the construction industry, the major industry player-owners, designers and contractors appear to be in conflict. These conflicts can be brought on by any number of situations, but the results from a lack of consideration about the real risks involved with a construction project. Risk Management involves appropriate handling of risks after evaluation and analysis to minimize the negative impacts risks have on the finance with the lowest costs. It is important for contractor to identify and analyze the risks that occur in design and build to ensure that it does not impede the success of the design and build project. In ideal risk management, a prioritization process is followed whereby the risks with the greatest loss and the greatest probability of occurring are handled first, and risk with lower probability of occurrence and lower loss are handled later. The process can be very difficult, and balancing between risks with a high probability of occurrence but lower loss versus a risk with high loss but lower probability of occurrence can often be mishandled. Risk management also faces a difficulty in allocating resources properly. Ideal risk management spends the least amount of resources in the process while reducing the negative effects of risk as much as possible. Proactive risk management doesn't necessarily mean avoiding projects that could incur a high level of risk. Formal risk management makes sure we go into such projects with our eyes open, so that we know what kinds of things that could go wrong, and we've done our best to make sure those factors won't prevent the ultimate success of the project. Risk management is a scientific approach to the problem of dealing with the pure risks faced by individuals and business aiming at systematically reducing the costs of risks and other inconvenience.

The main objective of risk management is to protect the continuity of operations also in case some threatening risk becomes a reality. Generally, risk management is a system to identify and quantify all risks to which the business or project is exposed so that a conscious decision can be taken on how to manage the risks. It must be practical, realistic and must be cost effective. Risk management also is a discipline for living with the possibility that future events may cause adverse effect.

Its principal aim is to ensure that risks associated with a construction project are managed in the most effective manner. According to Smith (1999), the process of risk management may be defined as identification of risk, analysis of the implications, response to minimize risk and allocation to appropriate contingencies 


\section{Methods and materials}

Questionnaire surveys were distributed to (60) respondents who are contractors under Grade G7 and who are registered under the Malaysian Construction Industry Board. A response rate of fifty-percent (50\%) was obtained. The purpose of the questionnaire survey was intended for a better feedback on the extent of the use of D\&B arrangement and the risk encountered during their projects.

The $2^{\text {nd }}$ part of the research involved an in-depth interview which involved (10) participants from various public and private companies. It was carried out with the senior managers to provide detail information on the background, knowledge and experience of $\mathrm{D} \& \mathrm{~B}$ project and the risks that occurred in design and build projects and ways to overcome them.

\section{Results}

A Likert-Type Scale of (5) which range from 1 to 5 where 5 are very important and 1 is not important was given to the respondent. Data obtained from the questionnaire survey were collected and analysed. Frequency counts and percentages of the data were computed. The average index used in order to analyse the data. In this research, average index was used. Results from the questionnaire surveys found that a majority of the respondents had prior experience on 1-5 projects. The others had undertaken 6-10 projects and only 7 respondents had embarked on the 10 projects. Fifteen (15) or $46 \%$ had experience in handling D\&B projects below 5 years. 27\% had experience of more than 6 years and nine (9) with experience of more than 10 years which includes projects such as hospital, school and commercial, residential and offices. Most of the projects included hospitals, schools, commercial buildings, residential buildings and others. Sixty-seven respondents $(67 \%)$ were involved in government projects while twenty-five $(25 \%)$ had experiences in private projects and eight $(8 \%)$ respondents were involved in both governments and project projects. Sixteen (16) respondents or forty-eight percent (48\%) of respondents had at least 5 projects in D\&B. Eight (8) or $24 \%$ had embarked on 6-10 projects, 6 respondents or $18 \%$ were involved in 10-15 projects and only 3 respondents had more than fifteen (15) D \& B projects.

From the analysis, it was found that time overrun and cost overrun, employer's/government delay, lack of information from the employer, difficulty of following instructions, conflict of interest and variation to changes were ranked as the highest risks in design and build procurement.

\subsection{Time overrun}

In D\&B projects, every contractor wants to avoid time overrun. Time overrun caused by contractors will not only effect the contractor financially but will also place the contractor's reputation at stake in handling D\&B projects. According to Contractor A, any kind of delay whether in the change of design and construction method, technical, environmental or government caused delays are main reason for time overrun. Most of the factors like risk changes that contribute to time overrun can be avoided even at early stage. The Employer plays an important role as well in ensuring that the project is completed within a stipulated time and cost.

\subsection{Cost overrun}

The client usually has a rough idea on what he wants in a D\&B project. Therefore, the D\&B contractors who bid for the tender will prepare a tender consisting of a brief design and also the cost to construct the project based on the requirements of the client. The tendered sum submitted by the contractor is usually fixed. Therefore, if the design-build contractor incurred extra cost because of his mistakes in the design or construction, he cannot claim from the excess from the client. When the client changes his mind on the design or the specifications, the contractor can claim the excess from the client causing the client to incur extra costs. This is because the client has agreed to the tender sum submitted by the D\&B contractor. The price submitted by the contractor covers all aspects of work from inception to completion; based on the brief and specifications required by the client. When the client finds a need to hire a consultant to work on his behalf, the professional fees paid to them will result in a cost overrun for selecting the D\&B contract. When there is any delay on time overrun, cost overrun will occur.

\subsection{Delay caused by the owner or the government}

When there is any delay in a project, time and cost overrun will occur. According to Contractor B, critical factors that are controllable during the design-construction process have been identified as insufficient owner-info, ill-conceived scheme of client requirement, changes of employer requirement, and significant changes to the original design, delay in approval and client initiated changes during construction. It shows that the clients themselves cause most of the factors that contribute to risk in time and cost. The clients have a precise understanding of the scope of projects before it is submitted to the D\&B team but once it is submitted, the clients always change the project scope or even the design. The government through its department such as the Environmental Department, Land Office, Electrical National Board, Water and Irrigation Department may also cause delays in D\&B projects. These various departments have their own laws and regulations that adhered to by the contractor to execute their work. Most of the time, the regulations change 
accordingly to current situations making such a way that the contractors have to deal with them. This will consume time. Problems like squatters which have to be dealt by the local authority were also time consuming thus causing further delay to the projects.

\subsection{Overlapping of roles}

In D\&B projects, the clients usually find that they still have to engage their own consultants, usually Project Monitoring Committee (PMC), for technical guidance and preparation of material setting out for their requirements. The difficulty with the preparation of the clients' requirement does not end at the preparation stage but many clients do not realize that their requirement will only amount to a schematic design of the end product. The concept behind the design-build contracts assumes that the contractor takes care of the detailed design and this is conferred a relatively wide mandate when interpreting the clients' requirements. According to Edwards, J and Bowen, A (2005), clients whom are new to the D\&B concept seem to find this mandate difficult to accept when they realize that they do not have the exclusive say or a free hand in deciding the implementation or outcome of the end product. Unfortunately, there is a tendency for clients who are new to the $\mathrm{D} \& \mathrm{~B}$ concept to issue numerous instructions through their representatives without realizing the full implications of such instructions. Prudent D\&B contractors will often ensure that their contractual rights are protected by notification of claims for delay, time related damages and actual costs for having to implement such instructions that are equivalent to variations orders.

Some clients when providing too many details may realize that they are doing what their contractor is being paid to do. Some other clients may not realize that they may be prejudice their contractual position by assuming responsibilities for parts of the design, particularly so if a detailed design is imposed on the contractor. Some consultants also provide full time supervision which is already covered by the in-house supervision. It is true that during the design phase and construction phase the contractor has complete control of matters but there are always interruption from the client's consultants regarding design correction, method and specifications. The contractors have always done their best in fulfilling the requirements. Many problems arise in the clients' consultant has differing opinions in particular types of construction or materials. What the contractor always does to solve this problem is to have a genuine discussion between both parties to agree on a solution. In most situations, the discussions will solve the problem. When this problem can lead to time overrun, extension of time (E.O.T) will be given. Another way to overcome the problem besides discussion is to ensure that the main-contractor can perform the job himself and not sublet the work to too many parties because this can place huge pressure on the sub-con who is actually executing out the work. All parties involved in the project must also be experienced and must establish their duties and responsibilities. These people should also understand the exact method of implementing the D\&B contract.

\subsection{Difficulty in adhering/following instructions}

The major difference for a contractor in $\mathrm{D} \& \mathrm{~B}$ contract is that it assumes liability for design. It is incumbent on the contractor to engage a design team to come up with a design that complies with the client's requirement. But for the inexperienced $\mathrm{D} \& \mathrm{~B}$ contractors, the selection of designers for the design team is vital. Not only should the contractor select team members that know how to integrate their portion of works into the overall design intended by the contractor but it is also imperative that each team members know how to receive instructions from the contractor. According to Contractor $\mathrm{C}$, a great number of consultants in our country are not accustomed to receive instruction from a contractor. Irrespective of the terms and conditions of the contract at hand where some consultants either consciously or sub-consciously attach more weight to the requirement of the clients rather than the contractor. These consultants appear to be entrenched in the traditional form of arrangements and are inflexible. As it is the role of the contractor to form the design team, the selection process for design consultants must be exercised with great care to ensure that they are able and willing to receive instruction from a contractor. To overcome this problem, the contractor must discuss the matter and remind the consultants whom they are working for and the design team should accept the orders from the contractors.

\subsection{Lack in employer brief}

The problem that normally arises in D\&B project is the bidding of the proposal. Most of the respondents think that lack of information in employer brief will create problem in the future. Normally, it happens in the local construction industry where the employer brief is not really complete. The client then will ask for changes during the construction. This will increase the cost and delay the project duration. According to Contractor D, a brief which is not detailed enough can be subjected to a lot of interpretations and understandings which could make the whole exercise futile and certainly not to the best interest of the client.

\subsection{Conflict of interest}

In D\&B contracts, the contractor provides the design and is usually perceived to have a conflict of interest because he also executes construction work. If the project is a direct negotiation with the contractor that means only one contractor will go for the tender. The clients may have their own idea or need in terms of design. However, because of e 
experience by the selected contractor, the employer's may be dissent. This is because the client still wants his idea and his needs to be catered to and the contractor suggestion. This will result in the late commencement of the work. The appointment of an independent professional to evaluate the design proposal may be a solution, but it involves additional cost.

\subsection{Variation to changes in design criteria}

Most of the details are not finalized for D\&B projects during the contract stage, and this increases the area of disputes, since changes are inevitable, particularly in large scale projects. Deviation from the original design will create higher risks for the contractor, for he has to pay for his own mistakes or decisions. This causes a variation. According to Contractors $\mathrm{D}$, if the variations come from the client, the extent to which the contractor can lodge a claim for abortive work and additional expense will depend upon the extent to which the original brief, specification and construction has been detailed and defined.

\section{Discussions}

Out of ten (10) interviews conducted, it was found that only seven (7) contractor who were that handling D\&B projects had experience in formal risk management, the other three (3) contractors used risk management in an informal approach. According to respondents, they must make sure that their application of risk management is efficient to the project. The right application can effectively reduce the probability of loss and increase the company's profitability.

\subsection{Risk identification}

From the interviews it was found that under risk identification method, the contractor used checklists methods, physical inspections, analysis of available records and brainstorming sessions. Eight (8) contractors informed that these methods are commonly used because they are reasonable and inexpensive, and their applications are simple and quick. For risk identification in a D\&B project, the respondents stated that they identified risk every month while other respondents identified risk in a particular project quarterly basis. According to them, the risks are controllable during the third quarter of the project duration, so these contractors felt it is best to identify risk on such a time frame. Risk identification depends on the overall condition of the project including its location, resources and work task. Therefore, different projects may require different modes of identification due to different factors.

\subsection{Risk analysis}

According to Contractor No.8, sensitivity analysis is commonly used because it is a simple technique. She also adds that although Monte Carlo testing is an efficient risk analysis system, it is seldom used by the contractor due to its complicated method. The testing has to be repeated hundreds or thousands time to obtain an accurate outcome. Besides, its implementation requires experienced personnel, suitable risk analysis training, applicable with computer software and specialist advice. These incurred cost for the contractor. The duration taken by the contractor to analyze the identified risk were mostly around $8-14$ days or around 2 weeks, and other contractor took only 7 days or a week to analyze those risks and to find a suitable response.

\subsection{Risk response}

According to the respondents, most of them favour to investigate the risks in order to reduce the probability of losses. However, only risks that have high probability of occurrence and high impact to the project will be managed.

\subsection{Problems encountered}

The problem encountered were the difficulties in evaluating tender. In D\&B proposal, however, each contractor submits his own design and price, and this makes evaluation very difficult, as the client is faced with different design proposals with differing prices. The situation can be further aggravated if a financing package is included in some of the proposals. The employer however, eventually decides to consider neither the lowest price nor the most aesthetic design but instead to concentrates on selecting the proposal that accorded best with the project brief. The selection problem can be overcome by reviewing all the proposals in totality and choosing the proposal which best meets the client's brief, and that which best offers the best value for money in all aspects. On the other hand, most of the respondents stated that problem also arise with work specification and definition. In D\&B contract, detailed design is usually involved only as work proceeds. As such, difference in opinion and interpretation of the specifications and requirements may develop between the contractor and employer. To reduce this, sometimes sophisticated specifications for major parts are needed right from the start. Poor quality of workmanship is also another problem. It was normally due to the sub-contractor selected by the employer and not by the D\&B contractor.

\section{Conclusion and recommendations}

It was found that changes of design scope by employer, over interference by employer consultant, variations with changes in design criteria, conflict in interest in design between employer and contractor, lack in employer's brief, force majored \& social disorder and employer's cause delays are critical risk factors in D\&B projects. 
In order to improve D\&B projects, it is recommended that contractors should have clear employer briefing, clear specifications and statement of needs, good quality of workmanship, implementing code of practice, key elements effective management, effective communication with all components of the project team and decisive action in the event of deviation from plans.

The results of the study are expected to provide useful guidelines for forming and operating effective and efficient D\&B projects in Malaysia and other countries. It can be concluded that risk management is a tool that must be applied in all $\mathrm{D} \& \mathrm{~B}$ projects in order for the construction and employer to achieve a satisfaction in a project.

In order to improve the $\mathrm{D} \& \mathrm{~B}$ system for further research, the following are the recommendation that need to be considered:

\section{1) Clear employer briefing}

Employer briefing is essential. The employer has to alert when giving the briefing. The briefing given at the initial stages of the pre-contract comprises all the employer's needs and requirement of the building. Another respondent gave the opinion that during the implementation of the D\&B project, the employer should be clear on a D\&B project. A clear briefing by the employer will avoid misunderstandings.

\section{2) Clear specifications and Statement of Needs}

The consultant has the main role in preparing a specification for the project according to requirements specified by the employer. A good specification will provide a clear picture for the contractor to implement the work on site. Besides that, a clear statement needs should be prepared by the employer. Clear specifications and need of statement will result in better execution of the project.

3) Good quality of workmanship

Several respondents thought that the employers and contractors should conduct more supervision work during the construction period. This supervision is essential to ensure that the contractor is regularly informed of the work progress that the employer is not cheated by the contractor. Both parties should work together during these supervisions.

4) Implementing code of practice

One respondent suggested that in improving the D\&B system and quality, some code/standard of practice should be enforced by the employer before getting involved in D\&B projects. This code/standard of practice is a guide in appointing D\&B contractor and consultants to ensure that the parties appointed are well-equipped and have sufficient experience in D\&B projects. The result of appointing suitable contractors and consultants is a proper implementation of work, the best of workmanship and better management by the employer and contractor.

\section{5) Proper Identification of the Employer's Requirement and Project Objectives}

Many problems on a project arise as a result of the project team designing something which is different from that which the developer needs. This is often a result of an inadequate understanding by the developer of his actual needs in building terms, and a misunderstanding by the D\&B team of the developer's objectives. If left unchecked, the confusion and discrepancy between employer's needs and the design proposal can result in unnecessary and abortive work by the D\&B team. The ineffective use of the design phase of the project programme can result in a less than ideal solution to the employer's requirement. Time invested by the developer and the D\&B team in a series of valuable management meetings during the early stages of the project can help to establish and prioritize the actual needs of the employer. The process of rigorous dialogues between both the employer and D\&B team can help to ensure the preparation of an appropriate brief. The process can also provide the D\&B team with a firm understanding of the employer's objectives for the project and their relevant priorities. The clear understanding of the employer's requirements can help the D\&B team to propose a design that meets the needs of the project, and prevents the abortive use of design time and resources in developing inappropriate design solutions.

\section{6) Key elements of effective management}

The successful management of projects undertaken by the D\&B method of procurement is found on the same principles as that are appropriate for all construction projects. The key difference is that by the selection of the D\&B arrangement, where one team is responsible from the concept to completion, greater potential and opportunity exist to practice effective project management. The key issue here is the opportunity to exercise control over all facets and phases of the project. As a result, no component of the project team is isolated from action taken by management in the event of difficulties. In particular, the project can be planned to aptly address the key requirements of each component of the team including specialist suppliers.

7) Effective Communication with all Components of the Project Team

One of the D\&B project manager's key tasks is the implementation and practice of an effective communications policy for the project. An effective communication process incorporates the construction programme into the design process. 
This can help to ensure that design information is always available to meet the needs of the construction stage. The communication process can contribute to an effective information management system. It is a coordinated flow of related information amongst all parties with regard to changes in design and requirement by authorities. The clear definition and co-ordination of communication between the different disciplines in the design team can help to reduce design problems.

8) Decisive Action in the Event of Deviation from Plans

Effective and decisive actions in the event of deviation from plans to recover the situation are vital to prevent the project from being disrupted. Should there be a situation where there are changes to the scope by the employer, the impact of the change on the project in terms of time, costs and quality must be communicated and understood by the employer.

\section{References}

Banks, E \& Dunn, R., (2003). Practical Risk Management, John Wiley \& Sons Ltd.

Beard, L.J., (2001). Design and Build: The Project Delivery Administration and Construction, McGraw Hill.

Carmicheal, D.G., (2000). Contracts and International Project Management, A.A. Balkema Publishers.

Chong, S.N., (2001). Mutation of Design and Build, Seti Putrajaya Sdn. Bhd., The Surveyor Vol.26, No.3 (3 ${ }^{\text {rd }}$ Quarter) 2001.

Dennis, F.T., (1995), Design and Build Contract Practice ( $2^{\text {nd }}$ edition), Longman Scientific and Technical.

Dulaimi, M.F, Morris, G.K \& Baxendale, T., (1998). Design and Build: The Need for Effective Design Management, The Surveyor Vol.33 No.1. ( $1^{\text {st }}$ Quarter).

Edwards, L., (1995). Practical Risk Management in the Construction Industry, Thomas Telford Publications.

Edward, R. Fisk., (2003). Construction Project Administration ( $7^{\text {th }}$ edition), Prentice Hall.

Flanagan, R \& Norman, G., (1993). Risk Management and Construction, Blackwell Scientific Publications.

Franks, J (1984). Building Procurement Systems, CIOB.

Knowles, R., (2000). 100 Contractual Problems and Their Solutions, Blackwell Science.

Masterman, J.W.E., (1992). An Introduction to Building Procurement System, E\&FN Spon.

Murcutt, A.G., (1998). Design and Build, CIOB.

Murdoch, J\& Hughes, W., (2000). Construction Contracts Law and Management ( $3^{\text {rd }}$ edition), E\&FN Spon.

Nael, G.B., (2003). Risk and Insurance in Construction ( $2^{\text {nd }}$ edition), Spon Press.

Standard Form of Design and Build/Turnkey Contract 2000 Edition, Public Work Department (PWD).

Smith, N.J., (1999), Managing Risk in Construction Projects, Blackwell Science Ltd.

The Aqua Group (1982), Tenders and Building Contract, Granada.

Wong, J, Inherent Problems in Design and Build and its Solutions, The Surveyor.

Standard Form of Design and Build/Turnkey Contract 2000 Edition, Public Work Department (PWD). 